Interdisciplinary Studies of Complex Systems

No. 17 (2020) 23-33

(C) L. Hubersky, L. Shashkova

https://doi.org/10.31392/iscs.2020.17.023

\title{
PHILOSOPHICAL EDUCATION: THE TURN TO THE APPLIED PHILOSOPHY
}

\author{
Leonid Hubersky ${ }^{1,2}$, Liudmyla Shashkova ${ }^{1,3}$
}

\begin{abstract}
Aim. Focusing on the substantiation of the process of modernization of the model of philosophical education, the study aims to represent the turn to applied philosophy as a new educational and professional program for training the philosopher. The theoretical basis of the study consists of two main points: the economic position of social epistemology, within which the emphasis is on understanding the social process of knowledge production and distribution of cognitive work, which requires a basis of interdisciplinarity. As well as practical application of a competent approach to philosophical education, which requires its modernization in the context of the requests and practices of today. Scientific novelty is to justify a turn to applied philosophy in the training of professionals, which enables practice in real-world situations and contexts beyond the realm of philosophy. The normative content of the preparation of the Master of Applied Philosophy, which is provided with a complex of competencies, is first formulated in the main learning outcomes as a methodology, moderation, performance. Practical significance. New techniques introduced in the program of applied philosophy, aimed at the organization and presentation of applied philosophical and scientific project, the purpose of which is to make their own intellectual inquiry in the chosen practical and applied fields. The transition from a rigid academicism to the reinforced practical aspect of teaching philosophy is fully explained in order for a new understanding of the role of university education to be understood. Namely: to ensure that the student's knowledge does not remain misconstrued or misused.
\end{abstract}

Keywords: applied philosophy, philosophical education, competencies, performance, moderation, interdisciplinarity, transdisciplinarity

\section{Introduction}

Modern fast and often unpredictable changes in the realities of social and individual existences in the World and the Ukrainian contexts cause a change in the very understanding of human preparation for life, philosophy of education and educational technologies, and in a broader sense - a more for a constructive socialization of an individual. As a global and central in the context of the reform of the education of the first quarter of the 21st century, the question arose as to what to teach and what priorities to choose in the organizational,

\footnotetext{
1 Taras Shevchenko National University of Kyiv, Ukraine

2 rector@univ.net.ua, https://orcid.org/0000-0002-4391-4385

3 profshashkova@gmail.com, https://orcid.org/0000-0002-2054-0405
} 
communicative, managerial dimensions, what competences should be formed specifically and in general, for a person to find his place in life, to be successful and competitive.

A modern university not only does provide a set of specific knowledge, but it also develops relevant skills in the field of the humanities / natural sciences for analyzing and critically comprehending material, conducting independent scientific research, applying evidence-based reasoning and methodological tools to solve problems in the field of cognition and activities. Such skills and competences are required by the modern information and innovation society [2]. The arrays of information that students have to work with are steadily increasing, so the learning process is geared to develop the ability to find in a huge amount of various sources and available information that will allow to successfully and effectively achieve the set goals, make sound forecasts, choose the best solutions in the best situation.

A systematic approach to the set of problems and problems that arise requires understanding at the philosophical level. Despite the informational multilayer and the constantly ongoing process of educational reform, the philosophy in the educational strategy system traditionally remains 1) integrative, 2) human-centered, 3) methodological orientation and fundamental fundamental. Referring to the European tradition, this means: first, justifying the unity of cognitive and educational practices; secondly (and perhaps first), the affirmation of the ideal of man and the broadest range of self-determination in the global world, given the particular sensitivity to value-based and cultural attitudes; third, understanding the latest trends in the development of science, its methodological tools, topics of interdisciplinary and transdisciplinary research.

In the current situation of increasing mobility, the conditions of activity and requirements for professional training are constantly changing, and in order for the educational model to become truly effective and successful, it must be oriented towards the formation of a complex of new type of abilities and skills, which enable rapid recognition of new and practice in real situations and contexts.

The purpose of this article is to focus on the substantiation of the process of modernization of the model of philosophical education, the study aims to represent the turn to applied philosophy as a new educational and professional program for training the philosopher.

Research done so far. The authors distinguish between the two main research vectors in the topic of transformation of philosophical education, taking into account changes in social and cultural realities, which is presented in the Ukrainian philosophical discourse. The first is based on the analysis of discussion materials and round tables presented on the pages of the professional journals "Philosophical Thought" [1 a, b, c], "Philosophical Problems of the Humanities" [4 a, b], "Philosophy of Education" [7], which are dedicated to clarifying the application of the competency approach. The transition to the principle of competency as the defining criteria for modern education (Report from the International Commission on Education for the 21st Century "Learning: The Treasure Within", 1996) is based on four main strategies: learning to know, learning to do, learning to live together and learning to be [7, p. 88]. Also, a competent approach is one of the priorities of the TUNING project and 
European strategies for creating a common educational space [6]. The authors of the article are involved in the development of standards of higher education in philosophy at the educational levels of bachelor, master and doctor of philosophy, made by a group of Ukrainian specialists (A. Karas, I. Karpenko, V. Menzhulin, S. Proleev, L. Shashkova) based on a competent approach. According to the four educational strategies mentioned above, they are aimed at shaping: the ability and heuristic thinking, the development of reflection and research consciousness, scientific and expert communication and adherence to scientific ethos and academic integrity [7, p. 91-95].

The theoretical vector of the study (being the second research one) is defined as the economic position of social epistemology (S. Fuller, F. Kitcher) $[9,12,13]$. Within its limits, cognition is viewed from an interdisciplinary perspective and requires the involvement of political, institutional, organizational, economic and other contexts to understand the social process of knowledge production and the distribution of cognitive work. This guideline is relevant to the rationale for turning to applied philosophy presented by the authors.

The scientific novelty of the study is to justify the turn to applied philosophy in the training of professionals, which enables practice in real-world situations and contexts beyond the realm of philosophy. The normative content of master's degree in applied philosophy, which is provided with a complex of competencies, is first formulated in the main learning outcomes as a) methodology, b) moderation, c) performance.

Research methodology. Modern science goes beyond laboratories and crosses disciplinary boundaries, leading to the formation of some new cognitive situations in which in search of its validity science makes a transcendent movement in the territory of life, responding to the requests and requirements of an applied strong field. Therefore, the autonomy of scientific knowledge is deeply disturbed, the boundaries of disciplines becoming flexible, the question of the combination of truth and practical utility rising. Scientific experience is being transformed into a new transdisciplinary amalgamation to absorb diversity and unity. Therefore, transdisciplinarity is a strategy for combining the progress of scientific knowledge and solving specific problems of oureveryday lifes.

It should be noted that the ideas of cooperation and the transfer of cognitive schisms from one disciplinary field to another uses an interdisciplinary approach, so there is a practice of using the terms "interdisciplinarity" and "transdisciplinarity" as synonyms. At the same time, some conceptual distinctions can be drawn. Interdisciplinarity is an interaction at the level from the simple exchange of ideas to the integration of disciplinary concepts and methodologies. Transdisciplinarity, though, means, in a narrow sense, the integration of different forms and methods of research to solve scientific problems. But "broadly" transdisciplinarity means rather "meta-methodology" and claims the development of a common system of foundations and the formation of common principles [3]. Increasing the value of problem-oriented forms of research activities (designing, forecasting, constructing) only reinforces the relevance of the application of a certain methodology. 


\section{Educational Strategy as Philosophical at its Very Core}

Can educational strategy be philosophically based? This question may seem rhetorical, but the positive answer to it is that philosophy has always appealed to the thinking of a human being, their ability to acquire knowledge that is not only a result of experience, enshrined in the form of clear and consistent provisions, but also a process to be learned.

The modern educational process is filled with life-practical concepts and questions that students need to understand through discussion, juxtaposition of opinions and approaches practiced in a real socio-cultural environment. The openness of philosophy is present in the educational process, both in the theoretical plane - discussions between representatives of different conceptual schemes, theories and paradigms, as well as in the practical sphere of communication and critical discussion. It is achieved by forming an independent position of the individual based on confidence in their knowledge and beliefs. But a person must be convinced of the effectiveness of his knowledge. It is well known that many conflicts are caused by a lack of awareness and understanding of the nature and specificity of the socio-cultural context in which a person is involved.

Thus, education changes its emphasis and the main indicator of effectiveness is the ability to independently acquire knowledge and apply them to solve non-standard tasks and problems, to act in unpredictable situations, and in the end - to realize their own project of self-realization. This leads to the transition to new educational technologies aimed at the formation of information-analytical and practically-oriented personality abilities, built on the use of the potential of interdisciplinarity and transdisciplinarity. In order to make such a transition, it is necessary to draw bridges between the theoretical and practical parts of teaching and teaching, which are often lacking in the real educational process.

As one realizes, the need to take into account the combination of knowledge and the world of life, theoretical understanding and the construction of new creative practices is predetermined by the purely philosophical task of finding a rationally understood path of man, leading to a worthy human existence. So, in the educational process, philosophy must be represented not only as a philosophical theory, but as a vital position. Both images define and combine the accentuated critical attitude of philosophy to the present state of affairs, to the critical analysis of values and life meanings, reflection on the principles of knowledge and culture. We are talking about the increasing attention that philosophy is paying to understanding the real social changes that challenge existing values. These are the processes of globalization, the social risks, the interaction of cultures and religions, the latest processes in the political, legal or moral spheres. That is, the current situation requires a person the ability to work not only with knowledge, but also with cultural situations, different mentalities, and in the end - with such complex complex problems, the understanding of which requires a systematic, complex thinking, able to work with new meanings and use heuristic tools.

The special requirements to the education system as the basic mechanism and means of purposeful formation of the person, its preparation for life and 
professional activity in the globalized world is the ability to respond as quickly as possible to new challenges and demands. Globalization processes form a new order of interaction of economic and political systems, change the concept of borders and borders, significantly expand cultural and informational contacts between peoples and states, which affects the activities of social institutions and processes. All of the above significantly influences the conceptual foundations of the modern model of education as a complex of competences, which defines the semantic horizon of the educational process.

A special place in the discussions of Ukrainian philosophers regarding the definition of complexes of competences in education is given to the discussion of the universal value of value-worldview competence for obtaining higher education in any professional field, i.e. the need to develop an educational standard of such competence as a general requirement for any specialty [4b, p. 55]. After all, value and ideological competencies play a significant role in professional success, provide the creative potential of the individual, the ability of intellectual search. After all, it is the solution of specialized professional tasks based on the acquisition of knowledge and skills in other sciences and subject areas. In addition, value-based competencies are the component of education that first and foremost ensures human effectiveness, its ability to meet the requirements of the modern world and to meet the needs of personal life. Moreover, the ability to live and professionally exercise oneself on the basis of the values and worldviews of humanity is inextricably combined with the skills of critical thinking, mastering and defending civic virtues, social responsibility and caring for the productive development of society and the state. However, the philosophical competencies offered by my fellow philosophers have not been included as general norms for the Bachelor's standard, but the discussions continue.

Discussion of the latest challenges to the education of the philosopher in contemporary realities touches many dimensions and aspects. There is a different understanding of the role of university education in the sense that the student's knowledge should not be left untapped.

\section{The Metaphor of "Knowledge Production" and Fair Distribution}

A set of questions regarding what knowledge has to convey and whether management needs such knowledge so that they are not left untapped is one of the realms of social epistemology. The focus of such developments is on the study of the social dimensions of knowledge or information, and more specifically, the study of social practices in terms of their influence on the true values of the beliefs of subjects (A. Goldman, D. Bloor, S. Fuller, F. Kitcher, etc.). That is, the task is to identify those social forces responsible for the production of knowledge and to study the peculiarities of the institutionalization of beliefs in a particular context. It is a question of combining social practices with the process of social production of knowledge, when the structure of knowledge and its content begin to be understood as social processes. In fact, this means that the problem of "knowledge production" arises with the active involvement of the economic context, when the knowledge society turns to knowledge management and the process of knowledge production and distribution is at the center of consideration. 
It should be noted that, compared to the earlier knowledge being evaluated in the light of one's own ideas, regardless of material factors, the economic perspective of understanding knowledge (in which cognition emerges as the activity of producing knowledge as material goods) is neither traditional nor familiar to the educational environment. Indeed, knowledge is associated with validity, truthfulness, reliability, as its essential attributes. However, such attributes testify to the boundaries of the study or the foundations of knowledge and do not explicitly indicate that it is inherent in the methodological autonomy of the research. The last from the point of view of social epistemology means that every process of knowledge production must be judged as the best, effective and successfully achieved. And truth and rationality are by no means the ultimate goals of the existence of knowledge production practices.

It is reinforced by such arguments and the position of modern economists, which is to believe that the active dissemination of knowledge turns it into the public good. This is especially true of the university, because it is within its limits that knowledge is produced as a product. One of the founders of social epistemology, S. Fuller, in the article "Social Epistemology of the University: How to Preserve the Integrity of Knowledge in the So-called Knowledge Society", analyzes ways of producing knowledge: "Method 1" — pure research, knowledge for the sake of knowledge; "Method 2" is modern [9, p.163]. The difference of methods encompasses the distinction between research driven solely by academic interests and research conducted in a more relevant social interest. In practice, Fuller points out, the possibilities of "Method 1" are closer to the possibilities of discipline or research program, and the concept of "Method 2" is much more blurred, it is closer to the concept of "market attractor". In essence, it is about understanding the purpose of knowledge, and ultimately, the goal of education, which is being transformed markedly in today's mobility environment. It is understood that the knowledge acquired by the student during the years of study can quickly lose its relevance and remain unused. And the educational model, which focuses only on knowledge, loses its effectiveness. It adds to the uncertainty of finding your place of intellectual work and the absence of constant inquiries. Therefore, on the one hand, it is important to manage the production and equitable distribution of knowledge, and on the other, to learn through engaging in real professional environments and social contexts.

S. Fuller proposed an economic metaphor for the conditions of knowledge production, and identified the problem of cognition in terms of the economics of text production. The author departs from classical individualism and argues that the individual cannot control and anticipate the results of his own cognitive activity, and that epistemic processes do not take place at the level of individual psychology. Knowledge is produced through social interactions and discursive practices. In order to understand this process, it is necessary to consider the processes of production and functioning of knowledge at the level of social interactions. The production of knowledge thus appears as a phenomenon more complex than that described by classical epistemology. Fuller redefines knowledge in terms of economics: the production of knowledge is an economic process, due to the fact that one has more knowledge, the other less. The fundamental issue is not the accumulation of knowledge but their fair distribution [13, p.29]. The process of knowledge production is considered by Fuller as consisting of two levels. The first level is at which each new 
knowledge redistributes the overall balance of awareness, and the second level is when knowledge is rather circulated and stored than transmitted. Therefore, "to have knowledge" does not mean to "possess knowledge", and the producer of knowledge, participating in cognitive processes, has the opportunity to make a profit on it.

Philosophers and economists view knowledge as a public good, given its free distribution, and special efforts must be made to limit this process. Therefore, in the long run, knowledge becomes available to practically everyone and increases the overall level of freedom and well-being. At the same time, concerted joint action is required to make knowledge universally accessible, but the real mechanism behind such efforts remains unclear. Indeed, the role of knowledge in the knowledge society has changed, the number of people who can receive university education has increased many times, university education has become widely available, so the university can be regarded as a kind of "business organization". In this case, the justification of knowledge management defines the "post-academic" concept of knowledge. From the point of view of social epistemology, the following question becomes relevant: is the ideal of knowledge autonomy undermined? After all, the classic mission of the university is to combine learning and research, and to preserve such integrity of knowledge requires a balance between the learning process and the focus on achieving competitive research excellence.

\section{The Turn to the Applied Philosophy}

Let us return to the consideration of the two main questions posed by the authors, but no longer in the theoretical but the practical and applied dimensions. That is, what should be the philosophical component of education and how can the model of philosophical education be modernized so that the knowledge acquired by the student in the learning process is not used? The practical answer to these questions was the introduction of a fundamentally new master's educational and professional program "Applied philosophy" at the Faculty of Philosophy of Taras Shevchenko National University of Kyiv [5]. Without exaggeration, the emergence of such a program in the academic educational philosophical space of Ukraine can be considered an important event that outlines a new strategy for solving the time-consuming tasks.

The idea to appeal to the Applied Philosophy as a whole is determined by the purpose of disseminating philosophical studies that have a direct practical dimension, address topics and issues in different areas of social life: economics, law, science, politics, medicine, education, etc. An example of this is The Routledge Handbook of Applied Epistemology, 2019 [10].

Applied turnaround in philosophical education is related not only to updating the disciplines of the curriculum, but its main strategy is the updating of methodological tools and teaching methods, which allow to form a complex of professional competences for the possibility of their application in various non-philosophical spheres. That is, philosophers are given the opportunity to work outside the realm of philosophy and in the boundaries with it. Therefore, the Master's Degree Program in Applied Philosophy focuses on the analysis of philosophical issues as they are presented in specific contexts, practices, and 
situations. The program is classically oriented to draw on the acquired knowledge of philosophy, but to be able to use them in a wider context, and not always this context is even humanitarian.

The defining goals of the program are set by its main vectors - Cognition, Communication, Values. Cognition: Critical Thinking, Innovation, Applied Cognition. Communication: Understanding Topics Emerging from Certain Social Issues Development in Complex Contexts that Require Teamwork, Common Experiences and Solutions, and the Application of Interdisciplinary and Transdisciplinary Strategies. Values: Rationale behind the Problem of different values, as they are Applicable to the Themes of Creating a Common Future Through the Incorporation of ideas of Humanity, Morality and New Technologies. Based on the above, applied philosophy is defined as an interdisciplinary sphere of philosophical discourse, focused on practical contexts and requests, monitoring contemporary socio-cultural practices, forecasting trends and consequences of their development. Applied philosophy, designed to develop new concepts for innovation and support critical thinking, serves as a communicative basis for the interdisciplinary linkages of philosophy, science and other fields of activity and current practices.

Responding effectively to new meanings and challenges, unforeseen situations, unfamiliar socio-cultural contexts requires appropriate training and learning. Therefore, the applied philosophy program focuses on reflecting on the principles of knowledge and culture, understanding the processes of social change and awareness of the possible risks, the presence of philosophy in the virtual space and social networks. The disciplines in the program are selected in such a way that they provide an opportunity to receive education not only for philosophers by profession, but also for specialists from other fields interested in teaching philosophy, in its application to solving practical and applied problems. In turn, such requests for the study of philosophy from outside contribute to the modernization of philosophical practices.

The list of disciplines in the program "Applied Philosophy" is organized as follows. 1) Normative disciplines: Innovative thinking; Communication and transdisciplinary discourse; Contemporary topography of philosophy; Civilizational perspectives of humanity; Modes of critical thinking; Diagnosis of our time; Practical analytics; Applied Rhetoric; Professional and corporate ethics. 2) Disciplines of specialization: Philosophical practices: criticism and introspection; Philosophical practices: philosophy of creative action; Philosophical practices: philosophical language, text; Philosophical practices: virtual space, social networks. 3) Disciplines to choose from, among which: Mentality and Economics: Causes of Nation's Wealth Formation; Anthropological horizon of culture; Innovative features of information societies; Science Art and others.

The new techniques introduced in the program are aimed at organizing and presenting an applied philosophical and scientific project, the purpose of which is to fulfill one's own intellectual inquiry in the chosen practical and applied field. To do this, theoretical studies will discuss the philosophical and scientific literature to build methodological work on the design of the future research program, and in practical classes the analysis and evaluation of the results presented for discussion. Depending on the topic chosen, the research project also includes fieldwork. These elements make up the philosophical 
and scientific performance as an independent creation of an intellectual event. Therefore, the normative content of the preparation of the Master of Applied Philosophy, which is provided with a set of competencies, can be formulated in the main learning outcomes as methodology, moderation, performance.

We describe the following results as an example of some of the major disciplines contained in the Applied Philosophy program. The leading idea of the course "Modern Topography of Philosophy" is the study of modern forms of functioning and places of presence of philosophical knowledge, peculiarities of its transformation, correlation of academic, public and applied philosophy on the basis of acquaintance with the real experience of philosophical activity in scientific and educational context of Ukraine. All the proclaimed dimensions form the basis for the preparation of an independent master's research project as one's own experience of monitoring, organizing and implementing research and educational projects in a real Ukrainian context. The applied teaching methods are aimed at obtaining the main result: self-realization of intellectual inquiry in the sphere of organization of philosophical space and management of philosophical-educational and philosophical-scientific projects.

The main purpose and result of studying the discipline "Innovative Thinking" is to create a philosophical and scientific innovative startup of humanitarian direction based on familiarization with real experience of innovative activity in the humanitarian sphere of modern Ukraine. As a result of their own research efforts, masters have to master the essence and features of innovative thinking, both through conceptualization of this phenomenon and real experience of its application in the humanities, mastering the skills and mechanisms of innovative thinking. An applied learning outcome is the development of a finalphilosophical-humanitarian project (startup) as one's own experience of innovative thinking.

The discipline "Communication and Transdisciplinary Discourse" focuses on the organization of applied philosophical and scientific research in the chosen field in order to demonstrate and improve the skills and competencies that enable modeling of communication situations, which allow one to act as a philosopher-moderator of a communication event or as a causal mediator during an event regarding humanities. Students must acquire new philosophical tools that provide contemporary communicative, interdisciplinary and transdisciplinary approaches. Theoretical and practical classes present a specific topic (updated today), which is constructed and analyzed as a complex communicative event. The researcher and participant in such an event should explicate the notion of "exchange zone" as a place where problematic communication occurs and propose their own scenarios for solving the proposed topic [8, 11]. Methodological tools are discussed in accordance with the presentation of complex problems as disciplinary, interdisciplinary and transdisciplinary.

One of the creative approaches to updating teaching methods is offered within the framework of the discipline "Models of Critical Thinking". The leading idea of this course is to create a philosophical and scientific performance of critical thinking in one of the proposed fields of application, namely, problem, disease, crisis, risk. The course is aimed at organizing applied philosophical and scientific research in the chosen field in order to demonstrate and improve the elements and skills of critical thinking. 
A distinctive feature of the discipline "Civilization Perspectives of Humanity", the sense hardwired to be herein with us is the creation of a philosophical and economic narrative of civilization in one of the proposed application areas. The philosophical and scientific narrative is represented as an independent creation of an intellectual situation with the aim of designing a common social future.

The discipline "Diagnosis of Our Time" is aimed at creating a philosophical and conceptual image of the Present as well as strategy for mastering theoretical understanding of the very present. Training course is focused on organization of applied philosophical and scientific analysis in multidimensional reality in order to obtain a meaningful interdependent (or "holistic") system of semantic coordinates for understanding the various phenomena and processes of the modern world. For this purpose, the lessons discuss the key historiosophemes of M. Heidegger and juxtaposition of their heuristic potential with other theoretical versions of modern times to build a systemic conceptual model of the present, as well as mastering the method of understanding the determining foundations of the organization and existence of the human world.

Therefore, any discipline of the program is organized as innovative and project-oriented since discussing the latest challenges of educating a philosopher in the Ukrainian reality touches upon multiple dimensions and aspects. It is a transition from rigorous academicism to strengthening the practical aspect of teaching, changing the format and model of the learning process: orientation to the development of intellectually innovative, communicative, creative skills, orientation to practical contexts and requests; a combination of interdisciplinary skills, mobility and competitiveness. Essentially, an applied philosophy program is experimental and needs adequate time to test its effectiveness and success, but the timeliness of implementing such a philosopher training program is obvious. In the end, there is a different understanding of the role of university education in the sense that the student's knowledge should not be left untapped.

\section{References}

[1] a) Academic philosophy. 2018. Philosophical Thought, 6; b) Philosophy in the public space. 2019. Philosophical Thought, 1; c) Philosophy at the University, 2013. Philosophical Thought, 5. [in Ukrainian]

[2] Zakon pro vyschu osvitu http://zakon4.rada.gov.ua/laws/show/1556--18; Zakon pro osvitu http://zakon5.rada.gov.ua/laws/show/2145-19. [in Ukrainian]

[3] Kiyashchenko, L. 2017. Events. Personality. Time. (To the philosophy of transdisciplinarity). Institute of philosophy of RAS. Russian Federation. [in Russian]

[4] a) Modernization of philosophical education: the potential of the master's programe. 2018. Philosophical Problems of the Humanities, 1(27): 5-21; b) Philosophy in the public space. 2019. Philosophical Problems of the Humanities, 2 (28): 5-13. [in Ukrainian]

[5] Master's program "Applied philosophy". 2018. http://philosophy.univ.kiev. ua/uploads/editor/Files/Osvit_nauk_prog. [in Ukrainian] 
[6] EU TUNING project, http://www.unideusto.org/tuningeu.

[7] Proleiev, S. 2016. Philosophical Competencies: What Should They Be? Philosophy of Education, 2 (19): 88-96. [in Ukrainian]

[8] Thagard P. 2014. Being Interdisciplinary: Trading Zones in Cognitive Science. Logos, 1 (97): 35-60. [in Russian]

[9] Fuller, S. 2008. Social Epistemology of the University: How to Preserve the Integrity of Knowledge in the So-called Knowledge Society. Epistemology \& Philosophy of Science, 1: 158-186. [in Russian]

[10] Coady, David and Chase, James. 2019. The Routledge Handbook of Applied Epistemology, New York, Routledge.

[11] Galison, P. 1999. Trading zone. Coordinating Action and Belief. The Science Studies Reader / Ed. by M. Biagioli. N. Y: Routledge.

[12] Kitcher, Philip. 1990. The Division of Cognitive Labor. Journal of Philosophy, 87: 5-22.

[13] Fuller, S. 2002. Social Epistemology. Bloomington: Indiana University Press. 